\title{
Gram Scale Synthesis of the Glucuronide Metabolite of
}

\author{
ABT-724 \\ Kenneth M. Engstrom, ${ }^{*}{ }^{\dagger}$ Jerome F. Daanen, ${ }^{\ddagger}$ Seble Wagaw, ${ }^{\dagger}$ Andrew O. Stewart ${ }^{\ddagger}$ \\ Global Pharmaceutical R\&D, Process Research \& Development, Abbott Laboratories, \\ 1401 Sheridan Road, North Chicago, Illinois 60064-4000 and \\ Department of Neuroscience Research, Abbott Laboratories, \\ 100 Abbott Park Road, Abbott Park, Illinois, 60064-6123 \\ kenneth.engstrom@abbott.com
}

\section{Contents}

General Experimental

Page

General Experimental

${ }^{1} \mathrm{H}-\mathrm{NMR}$ spectra of compound $\mathbf{1 7}$

S2-S3

${ }^{13} \mathrm{C}-\mathrm{NMR}$ spectra of compound $\mathbf{1 7}$

S4

${ }^{1} \mathrm{H}-\mathrm{NMR}$ spectra of compound 19

S4

${ }^{13} \mathrm{C}-\mathrm{NMR}$ spectra of compound $\mathbf{1 9}$

S5

${ }^{1} \mathrm{H}-\mathrm{NMR}$ spectra of compound $\mathbf{1 5}$

S5

${ }^{13} \mathrm{C}-\mathrm{NMR}$ spectra of compound $\mathbf{1 5}$

S6

${ }^{1} \mathrm{H}-\mathrm{NMR}$ spectra of compound $\mathbf{1 6}$

S6

S7 
${ }^{13} \mathrm{C}-\mathrm{NMR}$ spectra of compound $\mathbf{1 6}$ S7

${ }^{1} \mathrm{H}-\mathrm{NMR}$ spectra of compound $20 \quad$ S8

${ }^{13} \mathrm{C}-\mathrm{NMR}$ spectra of compound $20 \quad$ S8

${ }^{1} \mathrm{H}-\mathrm{NMR}$ spectra of compound $22 \quad$ S9

${ }^{13}$ C-NMR spectra of compound $22 \quad$ S9

$\begin{array}{ll}{ }^{1} \mathrm{H}-\mathrm{NMR} \text { spectra of compound } \mathbf{3} & \text { S10 }\end{array}$

$\begin{array}{ll}{ }^{13} \mathrm{C}-\mathrm{NMR} \text { spectra of compound } \mathbf{3} & \mathrm{S} 10\end{array}$

General Experimental: All reagents and solvents were used as received from commercial sources without further purification or drying. Unless otherwise noted all reactions are performed without the use of specially dried glassware and inert atmospheres. Air and moisturesensitive liquids were transferred via syringe. Organic solutions were concentrated using rotary evaporation below $35^{\circ} \mathrm{C}$ at 25 torr unless otherwise noted. Flash column chromatography was performed using commercially available pre-packed columns with an automated solvent pump and fraction collector. Analytical thin-layer chromatography was performed using glass plates pre-coated with silica gel impregnated with a fluorescent indicator. These plates were visualized using an acidic solution of ceric ammonium molybdate (CAM) followed by heating. HPLC analysis was performed on a Zorbax SB-C8 $4.6 \mathrm{~mm}$ by $25 \mathrm{~cm}$ column using an aqueous acetonitrile mobile phase with peak detection at $260 \mathrm{~nm}$. HPLC assay yields and HPLC purities were measured using standards that were deemed pure by HPLC and ${ }^{1} \mathrm{H}$ NMR analysis. Chemical shifts are reported in ppm ( $\delta$ scale) downfield from tetramethylsilane. For ${ }^{1} \mathrm{H}$ NMR, chemical shifts are referenced to the residual proton in deuterated solvents $\left(\mathrm{CD}_{2} \mathrm{HOD}: \delta 3.31\right.$; $\left.\left(\mathrm{CD}_{3}\right)\left(\mathrm{CD}_{2} \mathrm{H}\right) \mathrm{SO}: \delta 2.50\right)$. Data are given as follows: chemical shift, multiplicity, coupling constant (in $\mathrm{Hz}$ ), and integration. For ${ }^{13} \mathrm{C}-\mathrm{NMR}$, chemical shifts are referenced to the natural 
abundance of carbon-13 in the deuterated solvents $\left(\mathrm{CD}_{3} \mathrm{OD}: \delta 49.00\right.$; DMSO-d6: $\left.\delta 39.52\right)$.

Melting points were determined by DSC using a closed cup method and heating to $275{ }^{\circ} \mathrm{C}$ at $5^{\circ} \mathrm{C}$

per minute. Optical rotations are reported as follows: $[\alpha]_{\lambda}^{T \operatorname{deg} \mathrm{C}}(\mathrm{c}=\mathrm{g} / 100 \mathrm{~mL}$, solvent). 







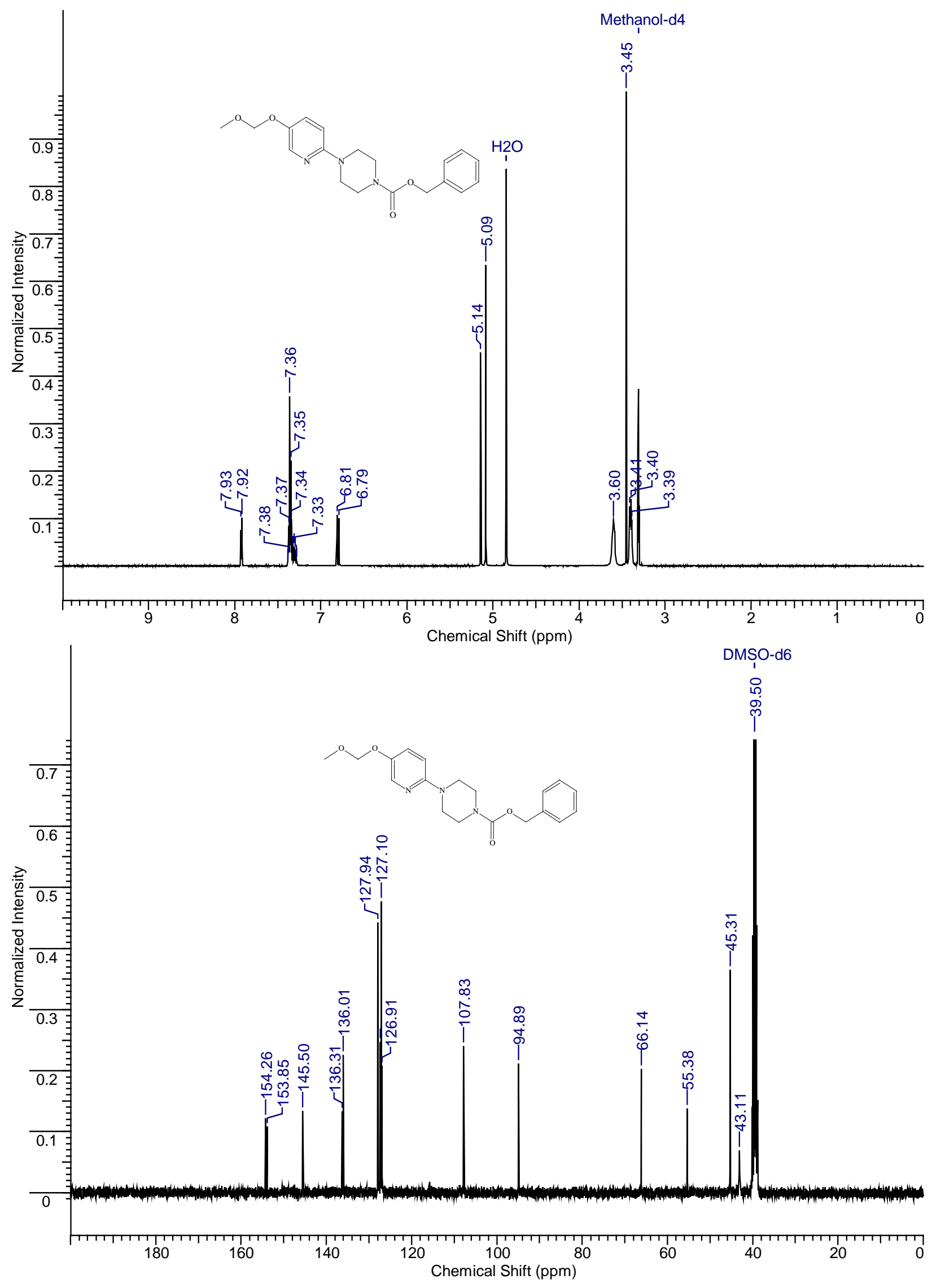




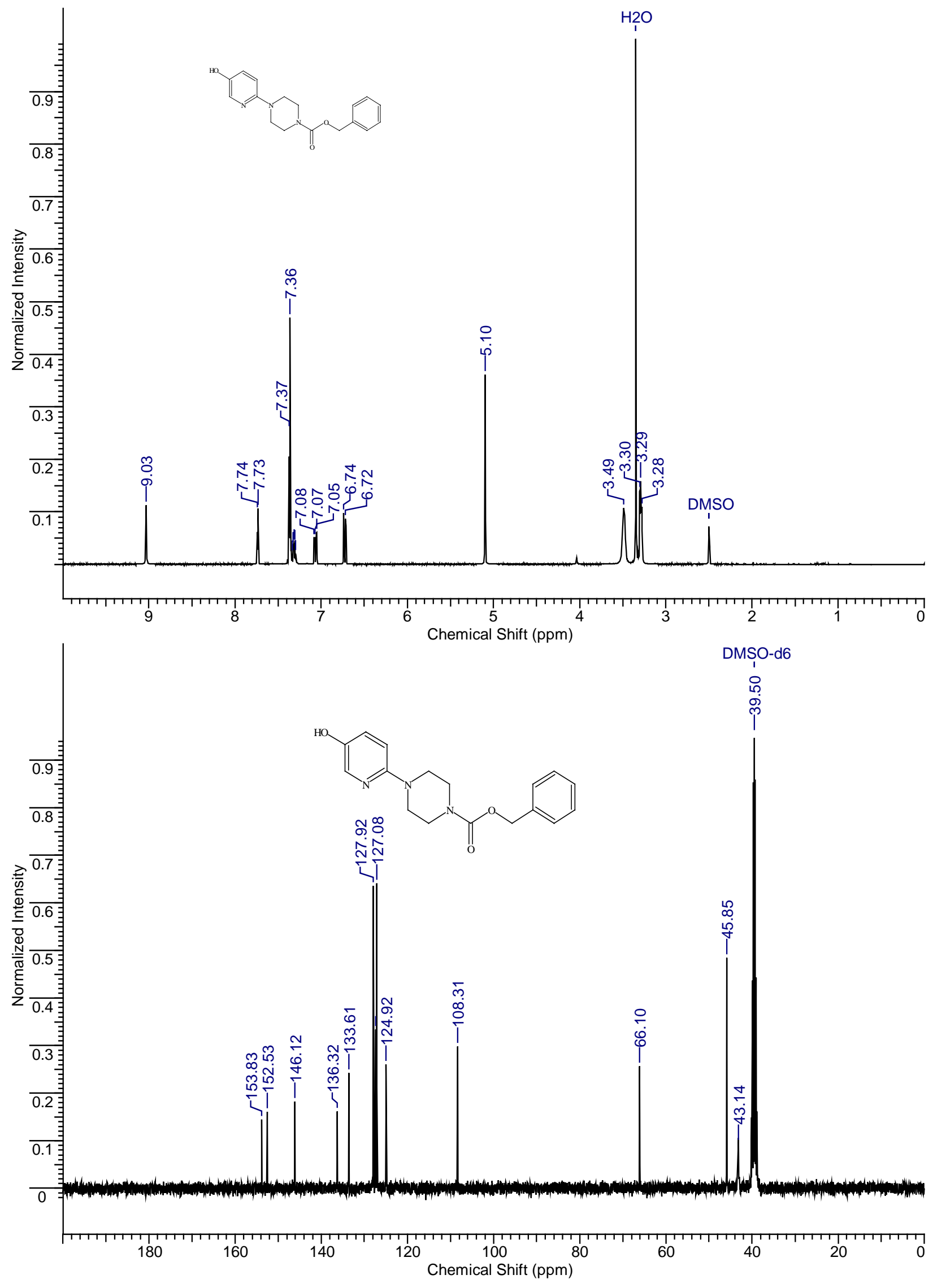




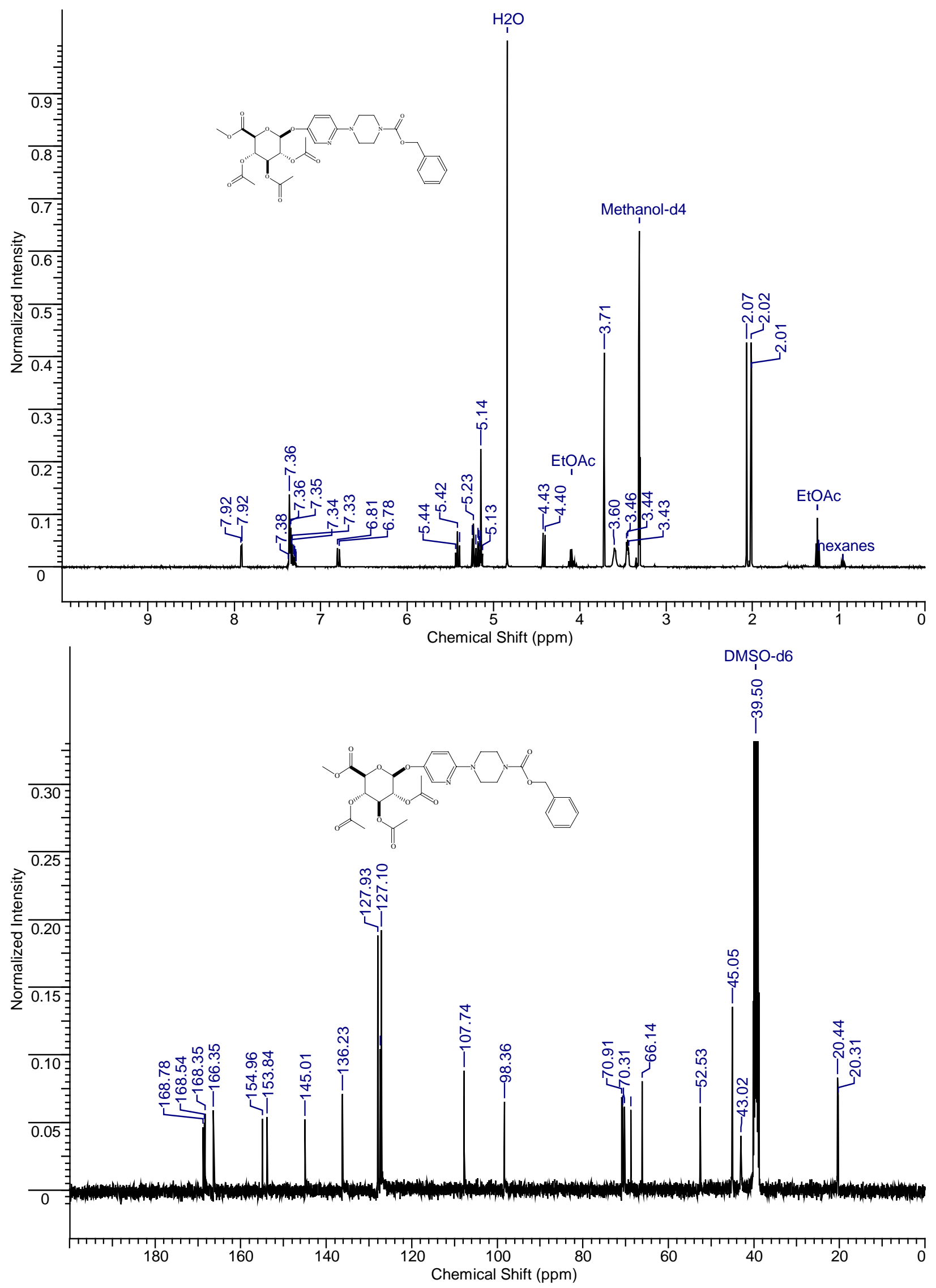



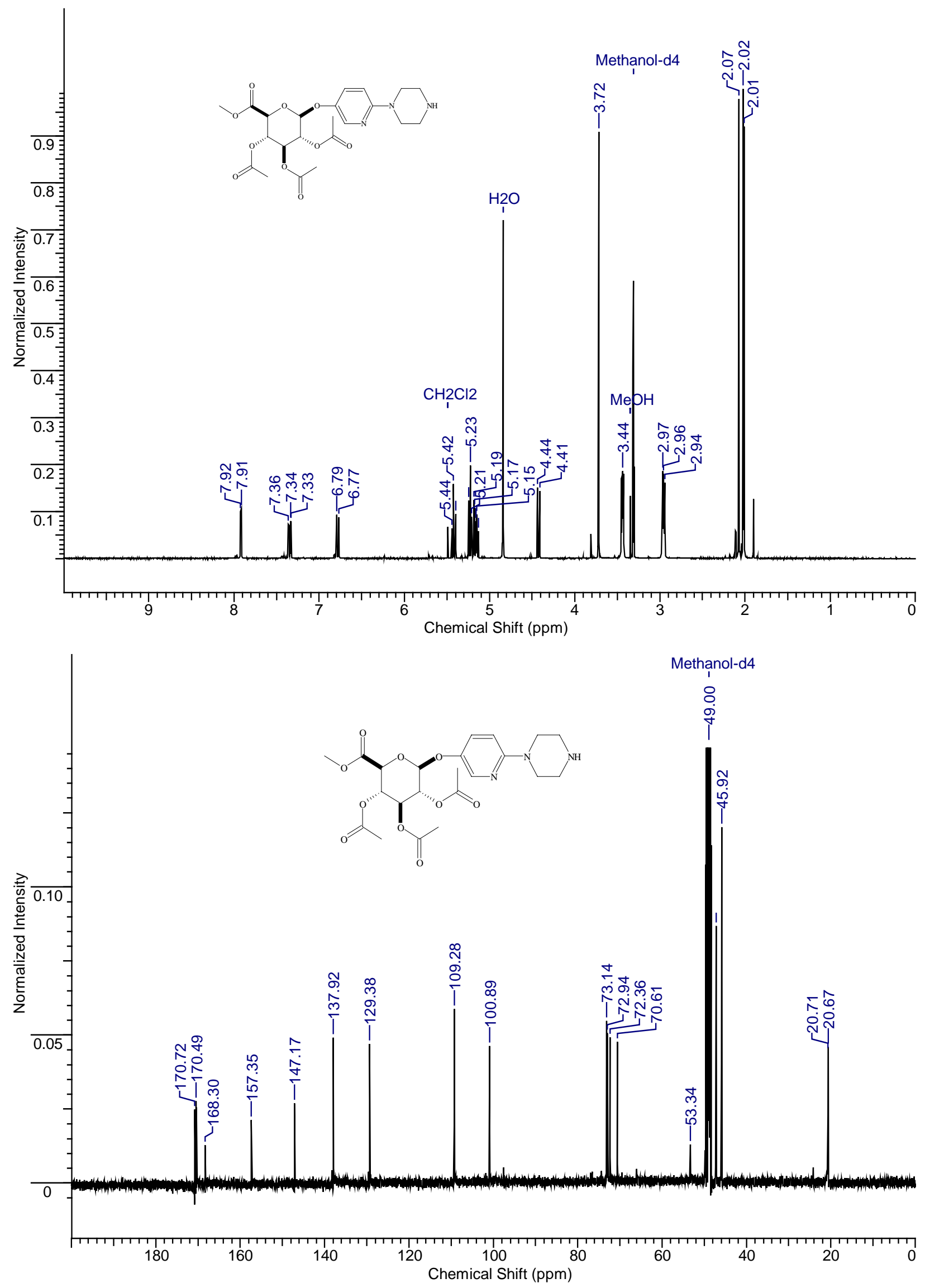


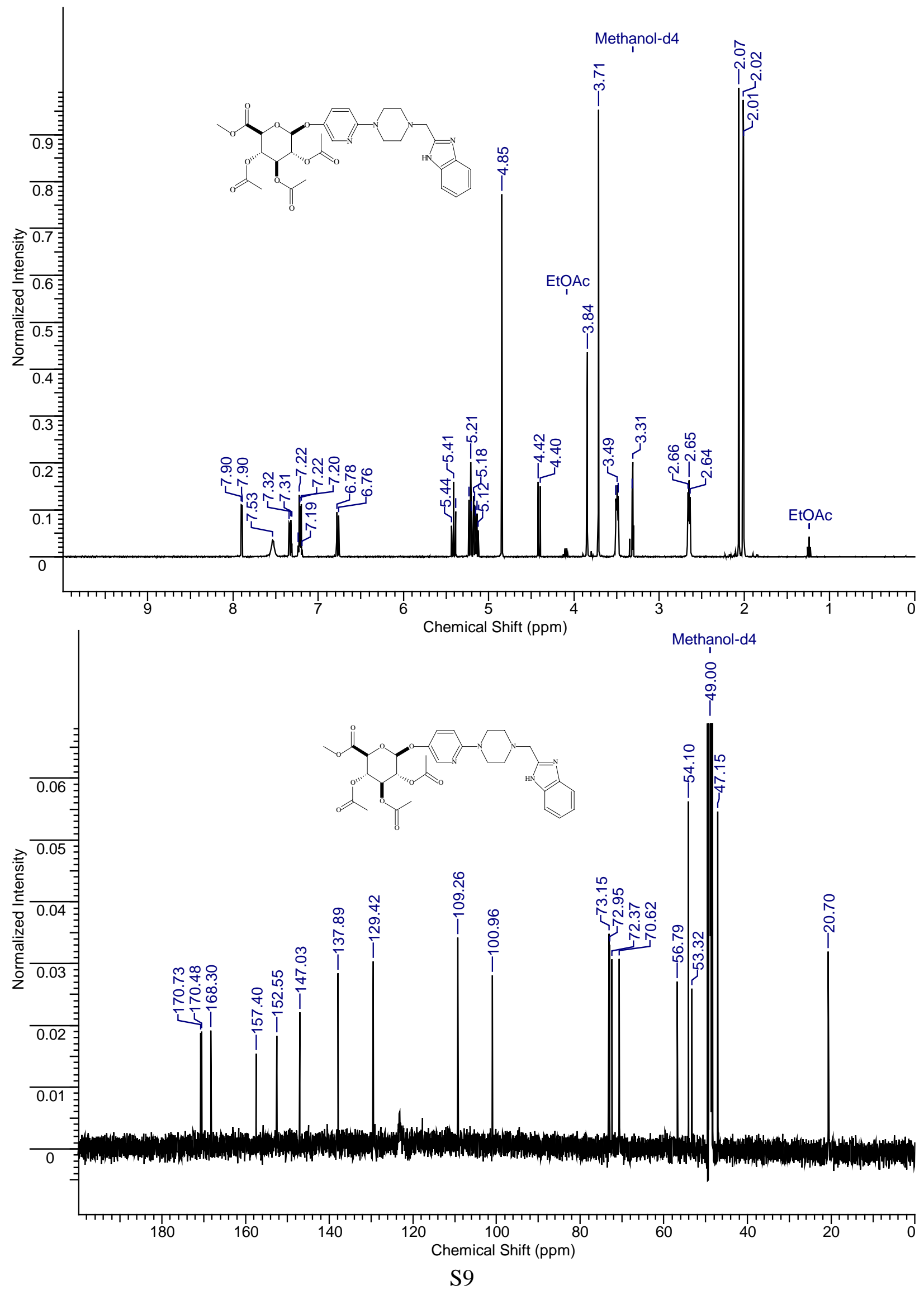



